\title{
United States physician communication on cost of cancer care under the affordable health care act
}

\author{
Laura L. Tenner, Aaron E. Carroll, Paul R. Helft \\ Indiana University, United States \\ Correspondence: Laura L. Tenner. Address: Division of Hematology/Oncology, Cancer Therapy and Research Center, \\ 7979 Wurzbach Rd., MC 8232, 6th Floor Urschel Bldg., San Antonio, TX 78229, United States. \\ E-mail: tennerl@uthscsa.edu
}

Received: May 19, 2014

Accepted: July 4, 2014

Online Published: July 24, 2014

DOI : $10.5430 /$ jha.v3n5p182

URL: http://dx.doi.org/10.5430/jha.v3n5p182

\section{Abstract}

Background: The aim of this study is to survey United States oncologists as healthcare system changes are implemented to reassess physician perceptions about the cost of cancer care and physicians' perceived needs.

Methods: From June through August of 2013, an electronic survey was sent to practicing oncologists across 50 states.

Results: The electronic survey response rate was 15\% (136 oncologists out of 899 total physicians) with respondents from 35 of the 50 states. Sixty percent of respondents thought that both out-of-pocket costs and healthcare system costs of cancer treatments were likely or extremely likely to have a larger effect on their decisions regarding which cancer treatments to recommend to patients in the future under the Affordable Care Act (ACA). A large majority of respondents felt that physician education was needed on the use of cost-effectiveness data and on communicating cost of therapies with patients, $91 \%$ and $85 \%$, respectively.

Conclusion: Respondents reported that their clinical treatment decisions are influenced by concerns over out-of-pocket patient costs, and that they want more cost and comparative effectiveness research as well as more education on how to communicate with patients about cost of therapy.

\section{Key words}

United States healthcare system, Affordable Care Act, Cost of cancer care, Cost-effectiveness, Comparativeeffectiveness, Cost communication

\section{Objectives, specific aims and potential significance}

In 2011, the Lancet Oncology Commission published an extensive review on delivering affordable cancer care in high income countries. They estimated the United States' total health care spending in 2009 was 2.5 trillion dollars, accounting for $18 \%$ of the GDP ${ }^{[1,2]}$. Roughly $5 \%$ of total healthcare spending was on cancer care ${ }^{[3]}$. Concern exists not only for the enormity of total spending on cancer care, but also the rate of increase. The Commission pointed out that the "increase in cost for cancer treatment could begin to outpace health-care inflation as a whole, and become responsible for the rising percentage of total health-care spending” ${ }^{[2]}$. 
The rising cost of cancer care had a significant impact on patients. In 2009, the United States bankruptcy filing rate among cancer patients was $2.1 \%$, up from $0.53 \%$ in $2004{ }^{[4]}$. In a 2006 survey of insured patients with cancer, a quarter reported that they had used most or all of their savings during treatment and that, concerning their medical bills, their insurance paid less than expected ${ }^{[5]}$. In a 2010 survey of physicians, 80\% of physicians reported that patients' out-of-pocket spending influenced their treatment recommendations ${ }^{[6]}$. Two thirds of physicians agreed that part of their role as physicians was to consider cost effectiveness when making treatment recommendations ${ }^{[7]}$. In a 2006 publication in Health Affairs Market Watch, Jacobsen, et al. found that reimbursement incentives did not affect oncologists' decision to treat metastatic cancer with chemotherapy, but did affect their choice of chemotherapy. Physicians were found to be more likely use therapies where profit margins were higher, either through negotiated discounts or more favorable cost to payment ratios ${ }^{[8]}$.

In an effort to expand healthcare coverage and control the costs of healthcare, The Patient Protection and Affordable Care Act (ACA) was enacted in 2010 and upheld by the U.S. Supreme Court in $2012{ }^{[9]}$. However, the implications of this legislation on cancer care remain somewhat uncertain. Albreit, et al., attempted to address the theoretical implications in 2011: In addition to expanding coverage to an additional 32 million Americans by 2019 and allowing survivors who have been previously denied coverage because of pre-existing conditions the ability to obtain insurance ${ }^{[10]}$, the ACA will impact reimbursement of cancer care through the creation of Accountable Care Organizations (ACOs) ${ }^{[11]}$. ACOs are partnerships between hospitals and physicians designed to coordinate and deliver efficient care and provide payment on the basis of value and quality rather than volume and intensity of services ${ }^{[11,12]}$. There is concern that, because of the changes made under the ACA, oncologists may find themselves on occasion in a place of competing obligations. The goal of the ACO is to urge oncologists to consider cost containment and resource distribution when considering treatment for patients while at the same time honoring their obligations to take into consideration the patient's autonomy and best interest. In order to navigate these competing obligations, physicians may have to engage in shared decision making and communication concerning cost and resource distribution in ways they have not previously.

In 2010, a national survey of medical oncologists found that less than half of physicians always or frequently discussed the cost of therapy with their patients ${ }^{[6]}$. However, this study was conducted prior to the passage of the ACA. With a changing health care system under the terms of the ACA focusing more on controlling cost of care, will physicians more frequently include financial discussions in their communication with patients concerning treatment plans? The present study was a response to the 2010 Neumann ${ }^{[6]}$ study challenge to resurvey oncologists over time as changes are implemented to reassess physician perceptions and physician needs.

The aims of this study included assessment of: (1) attitudes and current self-reported practice of U.S. oncologists concerning communication with patients about (i) out-of-pocket costs of therapy and (ii) societal cost of therapy; (2) how U.S. oncologists' perceptions of health care reform have affected their attitudes and self-reported practice concerning communication with their patients about (i) out-of-pocket costs of therapy and (ii) societal cost of therapy; and (3) U.S. physicians' self-assessment of and comfort with having discussions about out-of pocket and societal costs of therapy with cancer patients.

\section{Methods}

\subsection{Subjects}

Subjects were identified through a third-party vendor, Direct Medical Data (DMD), LLC, through their database from the American Medical Association master-file. The study was sponsored by internal funds from the Indiana University School of Medicine, Division of Hematology Oncology Department and the Charles Warren Fairbanks Ethics Department. The search criteria were limited to medical oncologists practicing within the United States. A list of 2,992 potential subjects 
from 50 states was generated. DMD uses an embedded icon technology that allows tracking of active email accounts by detecting if the recipients opened the email even if they chose not to complete the survey.

\subsection{Physician survey}

An electronic questionnaire was developed by the investigators, based on extensive review of the literature and previous surveys done in the same subject matter, and was refined by pilot testing among oncology fellows and faculty at our institution. The survey was designed to require no more than 10-15 minutes to complete. A random prize drawing for ten 50 dollar gift cards was offered as an incentive to complete the survey. Responders were assured of confidentiality and anonymity. Survey items included questions designed to assess current physician practices concerning communication of cost of therapy as well as oncologists' perception of how this may change under the ACA. The survey also included questions aimed to better understand physician perceptions of comparative and cost effectiveness data. Likert scales were used to measure responses in addition to soliciting free text comments. The survey and the study were approved by the Institutional review Board of Indiana University Purdue University at Indianapolis (please see attached survey).

\subsection{Deployment}

The survey instrument was deployed in four waves over June, July and August of 2013. Data were collected using an electronic survey online software (SurveyMonkey) which was uploaded to the DMD platform service for distribution. All emails to participants were sent through a DMD representative. The research team did not have access to the participants' names or email addresses. The only exception to this was for the participants who opted to self-disclose their email addresses for participation in the random prize drawing. These email addresses were removed from the main data set \& were destroyed once the prize drawing was completed. At the time of data analysis, there were no remaining participant identifiers (names or email addresses), only their self-disclosed demographic information.

\subsection{Data analysis}

Data from the survey were compiled and analyzed calculating the mean within data sets and using a z-test to compare across data sets.

\section{Results}

Four emails waves were sent out over a three month time period between the months of June and August. Of the 2,992 email addresses, 899 of those addresses were confirmed active. The survey was completed by 136 of the 899 oncologists who received the survey, for a final response rate of 15\%. Participants from 35 of 50 states representing four US regions: Northeastern states $31 \%$, North Central states $26 \%$, Southern states $26 \%$, and Western states $17 \%$. Please see the table for sample study characteristics.

\subsection{Perceptions on communication about cost of therapy}

Though $70 \%$ of respondents reported that out-of-pocket costs of therapy influence their treatment decisions, $48 \%$ of respondents either frequently or always discussed out-of-pocket costs, whereas only $37 \%$ discussed costs occasionally and $15 \%$ rarely or never discussed costs with their patients. When asked about healthcare system costs, $35 \%$ of respondents frequently or always discussed costs, $37 \%$ discussed costs occasionally and $28 \%$ rarely discussed healthcare system costs with patients. Only half of the responding oncologists reported that healthcare system costs influence their decisions regarding cancer therapies. No respondents answered that they never discuss healthcare system costs with their patient even though there was a small group of responders (2.2\%) who reported they never discuss out-of-pocket costs with patients.

When asked whether respondents feel it is important to discuss out-of-pocket costs with patients, $89 \%$ of physicians strongly or somewhat agreed ( $53 \%$ strongly agree). But when asked whether respondents think it is important to discuss 
healthcare system costs of cancer treatments with patients, $66 \%$ strongly or somewhat agreed $(p<.0001)(44 \%$ somewhat agree).

Table. Study sample characteristics, 2013

\begin{tabular}{|c|c|c|}
\hline \multicolumn{2}{|l|}{ Items } & \multirow[t]{2}{*}{ Percentage } \\
\hline Mean age (years) & $57(35-76)$ & \\
\hline \multirow{3}{*}{ Sex } & Male & $75 \%$ \\
\hline & Female & $24 \%$ \\
\hline & Other & $1 \%$ \\
\hline \multirow{8}{*}{ Practice Setting } & Private Practice & $41 \%$ \\
\hline & University Medical Center & $30 \%$ \\
\hline & Community Hospital & $17 \%$ \\
\hline & Health Maintenance Organization & $5 \%$ \\
\hline & Veterans Affairs & $2 \%$ \\
\hline & County Hospital & $1 \%$ \\
\hline & Public Health/Community Clinic & $0 \%$ \\
\hline & Other & $4 \%$ \\
\hline \multirow{4}{*}{ Region } & Northeast & $31 \%$ \\
\hline & North Central & $26 \%$ \\
\hline & South & $26 \%$ \\
\hline & West & $17 \%$ \\
\hline \multirow{2}{*}{ Board Certified in Oncology } & Yes & $98 \%$ \\
\hline & No & $2 \%$ \\
\hline \multirow{11}{*}{ Type of Cancer the physician treats } & General & $66 \%$ \\
\hline & Breast & $10 \%$ \\
\hline & Gastrointestinal & $2 \%$ \\
\hline & Genitourinary & $2 \%$ \\
\hline & Gynecologic & $1 \%$ \\
\hline & Head and Neck & $0 \%$ \\
\hline & Hematological & $6 \%$ \\
\hline & Lung & $8 \%$ \\
\hline & Melanoma & $1 \%$ \\
\hline & Sarcoma & $1 \%$ \\
\hline & Other & $3 \%$ \\
\hline \multirow{3}{*}{ Type of Community } & Urban & $48 \%$ \\
\hline & Suburban & $44 \%$ \\
\hline & Rural & $8 \%$ \\
\hline \multicolumn{2}{|l|}{ Mean \% of patients with Medicaid } & $11 \%$ \\
\hline \multicolumn{2}{|l|}{ Mean \% of patients with Medicare } & $42 \%$ \\
\hline \multicolumn{2}{|c|}{ Mean \% of patients with commercial/HMO } & $40 \%$ \\
\hline \multicolumn{2}{|l|}{ Mean \% of patients uninsured/self-pay } & $5 \%$ \\
\hline \multicolumn{2}{|l|}{ Mean \% of patients with VA Coverage } & $3 \%$ \\
\hline \multicolumn{2}{|c|}{ Mean \% of work week spent on clinical work } & $83 \%$ \\
\hline \multicolumn{2}{|c|}{ Mean \% of clinical revenue dependent upon clinical work } & $71 \%$ \\
\hline
\end{tabular}




\subsection{Perceptions on health care reform and communication on cost of therapy}

Of note, about half (49\%) of respondents reported that they were familiar with the provisions of the ACA. When physicians were asked whether they thought the ACA was likely to increase patients' out-of-pocket costs of cancer treatments, $43 \%$ responded that it was likely or extremely likely, 39\% responded that they were unsure and $18 \%$ responded that it was unlikely or extremely unlikely to increase out-of-pocket costs for patients. When asked whether the ACA was likely to cause an increase in healthcare system costs for cancer care, $43 \%$ responded likely or extremely likely, 32\% were unsure and $25 \%$ thought it was unlikely or extremely unlikely.

Furthermore, $60 \%$ of respondents thought that both out-of-pocket costs and healthcare system costs of cancer treatments were likely or extremely likely to have a larger effect on their decisions regarding which cancer treatments to recommend to patients in the future under the ACA. About two-thirds (68\%) reported that they would have to increase their communication with patients concerning both out-of-pocket costs and healthcare system's costs in the future under the Affordable Care Act.

\subsection{Physician's comfort with having discussions about cost of therapy with patients}

When asked whether physicians felt comfortable discussing costs of therapies with patients, $72 \%$ of respondents somewhat or strongly agreed that they felt comfortable discussing out-of-pocket costs with patients, whereas only $56 \%$ of respondents somewhat or strongly agreed that they feel comfortable discussing healthcare system costs with patients $(p<.007)$. Two-thirds of respondents (65\%) felt comfortable using cost-effectiveness information in treatment decisions.

\subsection{Perception on cost effectiveness, comparative effectiveness data, and government price controls on cancer drugs}

Sixty-seven percent of respondents reported that physicians should be making the decisions on whether a drug provides a good value. Only $4 \%$ of respondents thought the government should play a role in determining the value of a cancer therapy. Seventy-two percent of respondents felt cost-effectiveness data should be used in decisions to cover cancer treatments and $87 \%$ of respondents thought more research on comparative effectiveness of cancer drugs is needed. A large majority of respondents felt that physician education (91\%) is needed on the use of cost-effectiveness data and on communicating cost of therapies with patients (85\%). Fifty-three percent of respondents thought that government price controls for cancer drugs are needed.

Seventy-two percent of respondents agreed that patients should have access to cancer treatment regardless of out-ofpocket costs, and $56 \%$ of respondents felt patients should have access to cancer care despite healthcare system costs. When asked if every U.S. patient should have access to cancer treatments only if they are cost-effective, approximately $70 \%$ of respondents somewhat (39\%) or strongly (30\%) agreed.

\section{Discussion}

Results from this email survey study suggest that, during this time of a changing healthcare system environment, U.S. physicians report that their clinical treatment decisions are influenced by concerns over both out-of-pocket patient costs as well as healthcare system costs. Furthermore, more respondents reported that they feel more comfortable with using cost effectiveness data in their practices than they did in 2010 (65\% in 2013 vs. 42\% in 2010) ${ }^{[6]}$. However, it is interesting to note that physicians have not changed their reported communication with patients concerning costs of therapy despite their perception that they feel more comfortable with using cost effectiveness data. Increased physician familiarity with cost-effectiveness and comparative effectiveness data may be due to increased public awareness stimulated by coverage 
of the ACA. Yet we are not aware of any significant efforts aimed at physician training on how to communicate these complex cost issues to their patients.

Similar to the 2010 Neumann study, we found that physicians reported that they want more cost and comparative effectiveness research as well as more education on how to communicate with patients about cost of therapy ${ }^{[6]}$. These data suggest that educational efforts aimed at improving physicians' tools for communication about the costs of cancer care in order to have meaningful cost discussions with patients would be valuable.

\subsection{Physicians' perceptions of the ACA}

Almost half of the physicians surveyed reported familiarity with the Affordable Care Act, but there was no respondent consensus on how the ACA would influence out-of-pocket and healthcare system costs. Responding physicians were, however, confident that both out-of-pocket and healthcare system costs would play a larger role in their cancer treatment decisions over the next five years and that they will need to increase their communication with patients about both out-of-pocket costs as well as healthcare system costs.

\subsection{Who determines value}

Similar to the 2010 study ${ }^{[6]}$, the majority of physicians agreed that oncologists should make decisions about whether a cancer treatment drug provides good value. Despite the fact that physicians feel they should be the ones making the decision about therapy value, only $19 \%$ of physicians felt very comfortable using cost effectiveness data to determine treatment therapies. This may explain the increasing perception by oncologists of a need for research in both cost effectiveness (91\%) and comparative effectiveness data (87\%) as compared to the 2010 Neumann study (80\% $[p<.001]$ and $79 \%[p<.01]$, respectively) ${ }^{[6]}$ as well as a need for physician education on communicating cost (85\%).

Though only $4 \%$ of physicians thought the government should play a role in determining the value of a cancer therapy (compared to 21\% [ $p<.01]$ in the 2010 study), 53\% of physicians thought government price controls for cancer drugs are needed (similar to the $57 \%[p=.39]$ in the 2010 study). Physicians appear divided on the topic of government intervention on pharmaceutical price controls though they are unified in they appear resolved to maintain autonomy when it comes to decisions on therapy value.

\subsection{Limitations}

This study should be interpreted in light of several limitations. The response rate to this study was much lower than the 2010 Neumann study (16\% vs. 57\%) ${ }^{[6]}$ which may be due to multiple factors. This survey was an email survey as opposed to a postal survey, and email surveys have been found to have a much lower response rate ${ }^{[13]}$. Also, there may be physician burnout concerning discussion of the new legislation. Since the 2010 study, there has been significant debate with passing the ACA and a Supreme Court battle concerning the legislation. Respondents may also have self-selected based on interest in the issue.

Furthermore, not all questions were completed within each survey. If a question was left blank, it was not used to calculate the mean. The lowest "n” per question was 123.

Despite the low response rate, the study sample characteristics are almost identical to the 2010 study, with over 35 states contributed to the data, and there was a wide range of comments, both supportive of and opposed to the ACA legislation, suggesting that a more representative group was captured. Furthermore, physicians' reporting on frequency of communicating cost of therapy to patients as well as the influence of cost on therapeutic decisions, were very similar between the two studies, although the present survey adds data concerning new areas of interest not previously evaluated in the 2010 study ${ }^{[6]}$.

Political affiliation data were not collected because of concerns that it might negatively affect participation. 


\subsection{Future directions}

As accountable care organizations are put into practice, new demands will be placed on physicians. Oncologists will be positioned in key roles in which they will need to be actively involved in shared decision making discussions with patients on cost of therapy. Though many changes are being implemented in the new healthcare environment, few tools are available for physicians and patients to help them navigate through this shifting system.

The 2010 Neumann study ${ }^{[6]}$ data were collected in 2008, prior to the ACA legislation. It has been five years since that data collection and the same attitudes are observed, if not more so, of being ill prepared to address cost of therapy issues in practice. As legislation continues to be implemented and as new guidelines and pathways progress, it will be important to continue to resurvey physicians to see the impact changes have made. To the authors knowledge, no national surveys have studied patients' perception of communication on cost of therapy or its role in the decision making process. Such studies would also be valuable.

\section{References}

[1] Centers for Medicare and Medicaid Services. National Health Expenditure Fact Sheet. Baltimore: US department of Health and Human Services. 2009.

[2] Sullivan R, Peppercorn J, Sikora K, et al. Delivering Affordable Cancer Care in High-Income Countries. Lancet Oncol. 2011; 12; 933-80. http://dx.doi.org/10.1016/S1470-2045(11)70141-3

[3] Mariotto AB, Yabroff KR, Shao Y, Feuer EJ, Brown ML. Projections of the Cost of Cancer Care in the United States: 2010-2020. J Natl Cancer Inst. 2011; 117-28. PMid: 21228314. http://dx.doi.org/10.1093/jnci/djq495

[4] Mac Ready N. The Rising Cost of Cancer Care. Oxford University Press. 2011. http://dx.doi.org/10.1093/jnci/djr402

[5] The Kaiser Family Foundation. USA Today/Kaiser Family Foundation/Harvard School of Public Health National Survey of Households Affected by Cancer. November 20, 2009. Available from: http://www.kff.org/kaiserpolls/pomr112006pkg.cfm. Accessed February 10, 2010.

[6] Neumann PJ, Palmer JA, Nadler E, Fang C, Ulber P. Cancer therapy costs influence treatment: a national survey of oncologists. Health Aff (Milwood). 2010; 29(1): 196-202. PMid: 20048377. http://dx.doi.org/10.1377/hlthaff.2009.0077

[7] Schrag D, Hanger M. Medical Oncologists' views on communicating with patients about chemotherapy costs: a pilot survey. J Clin Oncol. 2007; 25(2): 233-7. PMid: 17210946. http://dx.doi.org/10.1200/JCO.2006.09.2437

[8] Jacobsen M, O’Malley A, Earle C, Pakes J, Gaccione P, Newhouse J. Does Reimbursement Influence Chemotherapy for Cancer Patients? Health Affairs. 2006; 25(2): 437-443. PMid: 16522584. http://dx.doi.org/10.1377/hlthaff.25.2.437

[9] Sebelius, V, et al. National Federal of Independent Business. June 28, 2012. Available from: http://www.supremecourt.gov

[10] Elmendorf, D. Letter to the Honorable Nancy Pelosi. Cost estimate for the amendment in the nature of a substitute for H.R. 4872, incorporating a proposed manager's amendment. March 20, 2010. Available from: http://www.cbo.gov/ftpdocs/113xx/doc11355/hr4872.pdf. Accessed August 30, 2010.

[11] Albright H, Moreno M, Feeley T, Walters R, Samuels M, Pereira A, et al. The Implications of the 2010 Patient Protection and Affordable Care Act and the Health Care and Education Reconciliation Act on Cancer Care Delivery. Cancer. Apr 15, 2011; 117(8): 1564-74. PMid: 21472704. http://dx.doi.org/10.1002/cncr.25725

[12] McDonough J. The Road Ahead for the Affordable Care Act. N Engl Med. 2012; 347(3): 199-201. PMid: 22747178. http://dx.doi.org/10.1056/NEJMp1206845

[13] Shin E, Johnson T, Roa K. Social Science Computer Review. 2012: Survey Mode Effects on Data Quality: Comparison of web and mail modes in a US National Panel Survey. 2012; 30(2): 212-228. 